\title{
Optimal tube diameter on heat exchanger shell and tube type with 15 mega watt thermal power using fluent 6.3
}

\author{
Siti Nurhasanah $^{1, *}$, Muhammad Subekti ${ }^{2}$, Moch. Nurul Subkhi ${ }^{1}$, and Bebeh Wahid Nuryadin ${ }^{1}$ \\ ${ }^{1}$ UIN Sunan Gunung Djati Bandung, Jl. AH. Nasution No.105 Bandung, Indonesia \\ ${ }^{2}$ National Nuclear Energy Agency of Indonesia (BATAN), Center for Nuclear Reactor Technology and Safety, Puspiptek Area Serpong, \\ Tangerang Selatan 15310, Indonesia
}

\begin{abstract}
Heat exchanger shell and tube type is a set of tools that serve to move the heat from the side shell (hot fluid) to the tube (cold fluid). RSG-GAS Heat Exchangers is a heat exchanger shell and tube type 2-2. Since the age of Heat Exchanger operation long enough allow for new designs of heat transfer better. This is one reason the presence of micro modeling using Computational Fluid Dynamics (CFD), as one of them using the software FLUENT 6.3. Tube and shell modeled in GAMBIT with the variation ID (inner diameter) tube. As for the physical data such as flow rate, pressure, and temperature refers to the RSG-GAS Heat Exchangers. The first variation is the different mesh sizes for the tube that has the same diameter. Mesh size of $0.8 \mathrm{~mm}$ had the best result so do the meshing used as a benchmark for other models. Variations of 2D models use inner diameter from $20 \mathrm{~mm}$ until 26m. From CFD calculations using FLUENT 6.3 for 2D models, in the can that ID $20 \mathrm{~mm}, 23 \mathrm{~mm}$ and $26 \mathrm{~mm}$ can be used as models for 3D calculations. Of 3D calculations it can be concluded that the tube with an ID of $26 \mathrm{~mm}$ have the most optimal heat transfer is equal to $273,24669 \mathrm{~K}$ with a pressure drop of $450 \mathrm{~Pa}$.
\end{abstract}

\section{Introduction}

The demand for energy in the form of electricity is the greatest, even with the deregulation in the economic sector, industrial activity increases more rapidly so that the demand for electric power increases also exceeds the original estimate. The current use of nuclear energy is of interest to many countries, because the amount of fuel available in the world is large enough, so for the price it is expected to be stable and cheap [1].

The issue of Indonesia will build a Nuclear Power Plant (NPP) is likely to become a problem in the future. One of the steps that Indonesia has taken as the beginning of this nuclear power plant is to build three research reactors in three different cities. In Indonesia, the history of the nuclear reactor began on 5 December 1958 with the formation of the Nuclear Power Weapons (LTA) with the task of undertaking research and development of nuclear energy. This date is the birth date of the National Atomic Energy Base (BATAN) [2].

The first research reactor built in Indonesia was TRIGA MARK I reactor built in Bandung with $250 \mathrm{~kW}$ power on 19 April 1961. Then 16 years later, a $100 \mathrm{~kW}$ Kartini Reactor was built which was operated in Yogyakarta city. Not long ago, precisely in 1987, Indonesia built Multipurpose Reactor - GA. Siwabessy (RSG-GAS) with greater power than the previous reactor that is $30 \mathrm{MW}$. The reactor is operated until now and is located in Serpong, Tangerang.
Many systems are involved in a nuclear reactor, one of the most important systems is the reactor cooling system itself. The reactor cooling system determines the heat transfer resulting from the fission reaction. One part of this cooling system is the Heat Exchanger. Heat Exchangers transfer heat from primary fluid to secondary fluid. In addition to research reactors, Heat Exchangers are widely used in industry and energy generation such as nuclear power plants, power plants, power plants and others.

In a research reactor, the probability of malfunction of components, systems and structures will increase with the age of the reactor due to the degradation caused by the aging process. The aging management activities in it include protective, repair and replacement activities of components as appropriate for maintenance activities [3].

In the heat exchanger industry is a vital equipment, especially in industries that use or process energy. Efforts to improve the effectiveness of heat exchangers need to be improved. According to the Asian EC Energy Management Training and Research Center (AEEMTRC) conducted a study in 1990, that with an increase of 5\% heat exchanger effectiveness will save energy in the industrial sector, equivalent to 1 million tons of oil in 2000 [4].

Heat exchanger is one of the important components used in the industry and power plant so o enable the existance of new design that can produce optimal heat transfer $[5,6]$. RSG GAS has had a long operating time so that the aging process, as well as the heat exchanger which

\footnotetext{
*Corresponding author: siti_nurhasanah@uinsgd.ac.id
} 
is one of the components in it. This aging will result in more material degradation compared to normal conditions, which will change the nature and character. Therefore it is necessary to disrupt or manufacture heat exchangers more effectively and efficiently.

Many methods are used to get new design of Heat Exchanger [7-9]. One of them is used Computational Fluid Dynamics (CFD) [10-12]. CFDs are a set of computer-using methodologies for simulating fluid flow, heat transfer, chemical reactions, and other flow phenomena by solving numerical Navier-Stokes equations. In this study, the calculation used FLUENT and GAMBIT.

This main purpose of this study is to know the optimal diameter of the heat exchanger so it can be produce maximum heat transfer [13]. Thisexperiment consist of 2D (Dimension) dan 3D model. All models are made in GAMBIT. The results of GABIT will be given various agnitudes and boundary conitions then calculated using FLUENT

\section{Result and Discussion}

\subsection{Data of Heat Exchanger RSG-GAS}

Table 1. Data of Heat Exchanger RSG-GAS.

\begin{tabular}{|l|l|}
\hline Heat Exchanger Diameter $(\mathrm{mm})$ & 1300 \\
\hline HeatExchanger Radius $(\mathrm{mm})$ & 650 \\
\hline $1 / 2$ Heat Exchanger Area $\left(\mathrm{mm}^{2}\right)$ & 663.325 \\
\hline Number oftube $1 / 2$ Heat Exchanger & 816 \\
\hline Flow Rateshell side $(\mathrm{kg} / \mathrm{s})$ & 430 \\
\hline Flow Ratetubeside $(\mathrm{kg} / \mathrm{s})$ & 485 \\
\hline Area of triangular model $\left(\mathrm{mm}^{2}\right)$ & 389.7 \\
\hline
\end{tabular}

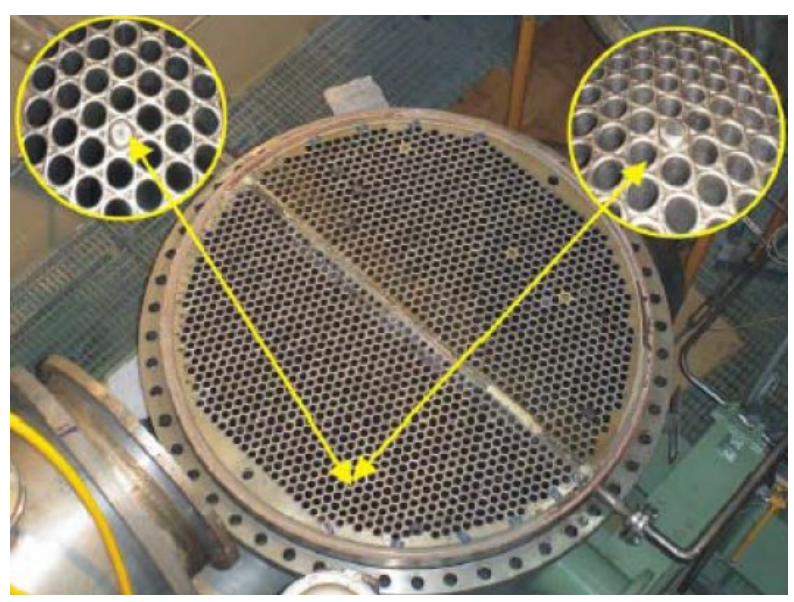

Fig. 1. Cross Section Shell and Tube Heat Exchanger RSGGAS.

The picture above shows the shell and tube of RSGGAS. The total number of tubes is 1632 tubes. The shell in the Heat Exchanger RSG-GAS is traversed by a hot fluid flowing between the tubes with the other tube, while the tube itself is fed by cold fluid.

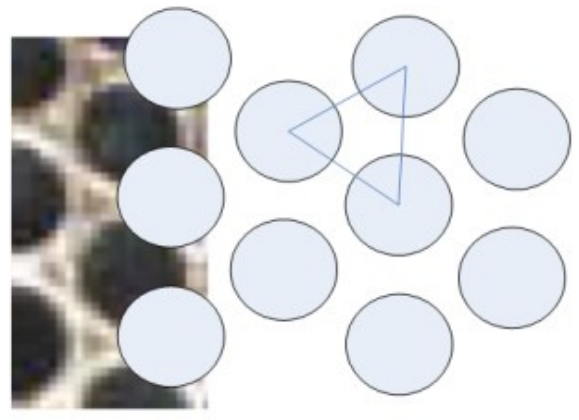

Fig. 2. Heat Exchanger Tube.

The picture above is the tube model will be created in GAMBIT. The three tubes have the same diameter, so that the distance between the adjacent two-tube (pitch) center points is the same size. Therefore, the equilateral triangle above can be modeled for in GAMBIT as it has represented the primary and secondary streams in the Heat Exchanger. The location of the shell in the triangle model is in the middle of the triangle.

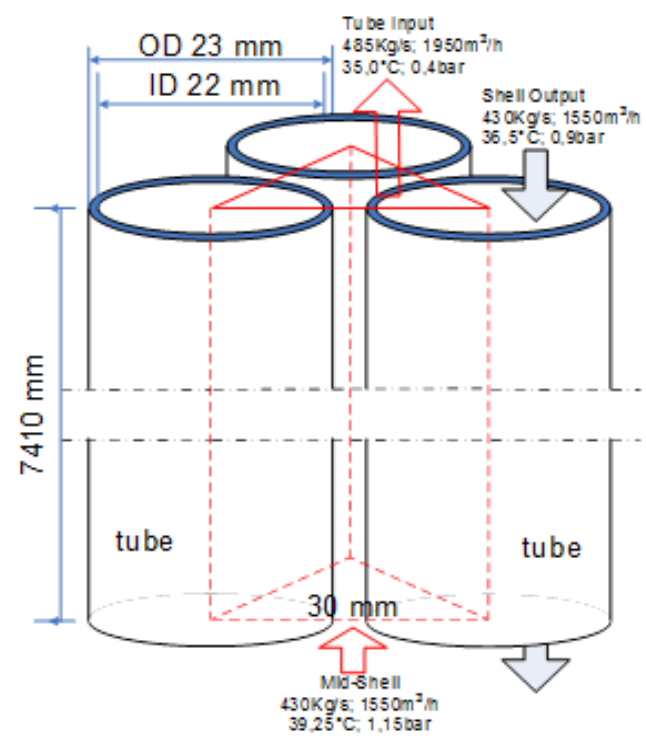

Fig. 3. Heat Exchanger Shell and Tube 2-2 model 3D in GAMBIT.

The inner diameter and outer diameter of one tube to be modeled in GAMBIT has the same size as the tube on the actual Heat Exchanger. What is different is the height of the tube itself. This will affect the entry temperature for cold and hot fluids. In the above triangular model, the fluid flow to be taken and calculated comes from 1/6 tube so that the values for both primary and secondary flow rates will be much smaller than the actual value. In GAMBIT, the geometry for the 2D model as shown below: 


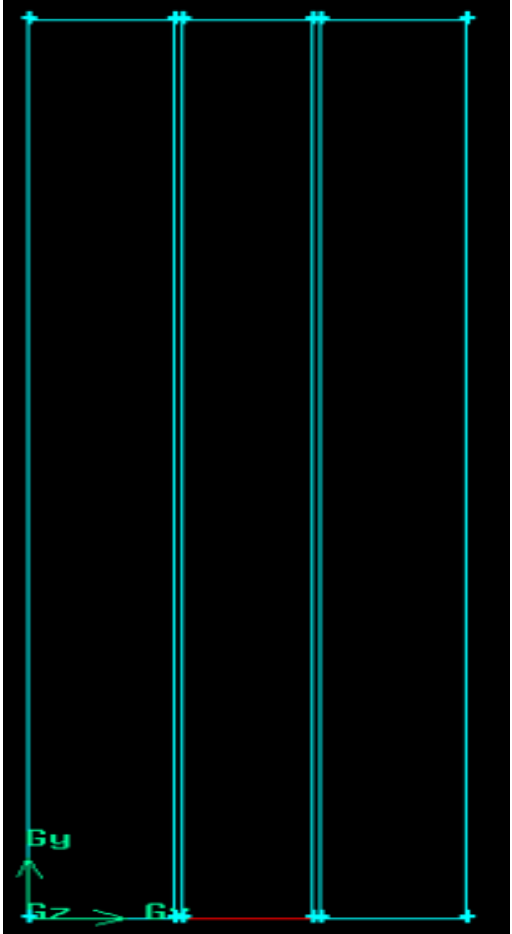

Fig.4. 2D Model Image.

The image above shows the $2 \mathrm{D}$ model where the square on the right and left is the tubes while the center is a shell. A small section between the shell and tubes is considered a wall.

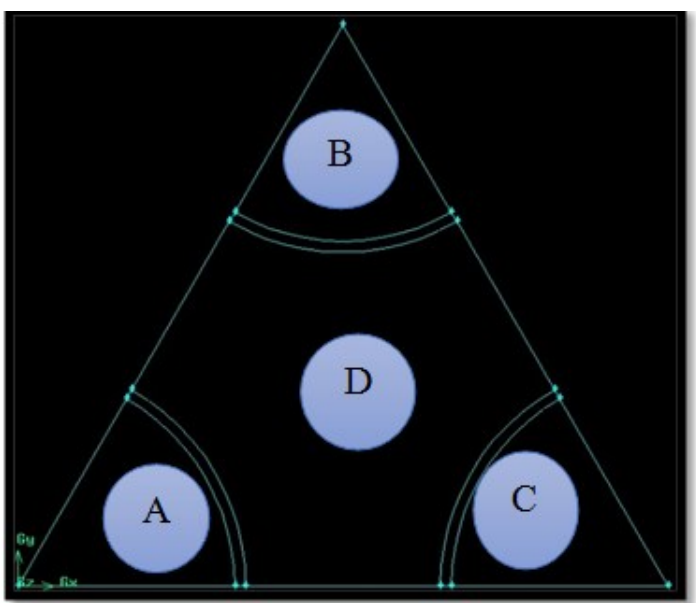

Fig. 5. The Top of 3D Model.

The image above shows the top of the 3D model. Part $\mathrm{A}, \mathrm{B}$ and $\mathrm{C}$ are tubes flowed by cold fluid. Part $\mathrm{C}$ is a shell which flows through hot fluid.

\subsection{Variations of 2D Models with Inner Diameter Variations}

Calculations for Heat Exchanger 2D model with height of $100 \mathrm{~mm}$ have been done with variation of Inner Diamater (ID) $20-26 \mathrm{~mm}$. This variation is performed to find out which ID can produce the most optimal heat transfer.
Prior to the calculation with the variation ID, mesh size determination steps to study the characteristics of the calculation results and find out the best mesh size for the model that has been made. The best mesh size will be used later in the calculation of CFDs in the variation ID. This mesh size variation is done with 3 variations of mesh with size $0,2 \mathrm{~mm} ; 0.5 \mathrm{~mm}$; and $0.8 \mathrm{~mm}$.

From the calculation, $0.8 \mathrm{~mm}$ mesh size takes time to reach the fastest convergent. Therefore, for time efficiency, iteration uses a mesh size of $0.8 \mathrm{~mm}$. The iteration process stops when the CFD calculation has been convergent meaning it has fulfilled the specified residual value of 10-6. In this case the residual control is monitored only by 3 parameters ie energy equation and k-epsilon. As the above explanation shows that the mesh size of 0.8 gets the fastest convergent convergence time.

The results of CFD calculations that can be analyzed are those that have reached convergent. Each ID can reach converge in different iterations. The number of iterations so convergent produced for each ID can be seen from the table below.

Table 2. The number of iterations until convergent for each ID.

\begin{tabular}{|c|c|}
\hline ID & Number of iterations \\
\hline 20 & 1199 \\
\hline 21 & 1259 \\
\hline 22 & 1386 \\
\hline 23 & 1447 \\
\hline 24 & 1575 \\
\hline 25 & 1709 \\
\hline 26 & 1781 \\
\hline
\end{tabular}

As seen in the table above, the larger the ID, the number of iterations to converge more and more. To further facilitate the analysis, the results of CFD calculations in the form of temperature contours for all IDs will be created in one thickness so that it can be seen the difference between IDs with each other. Temperature distribution within the shell will be made apart with the temperature of the fluid present in the tube.

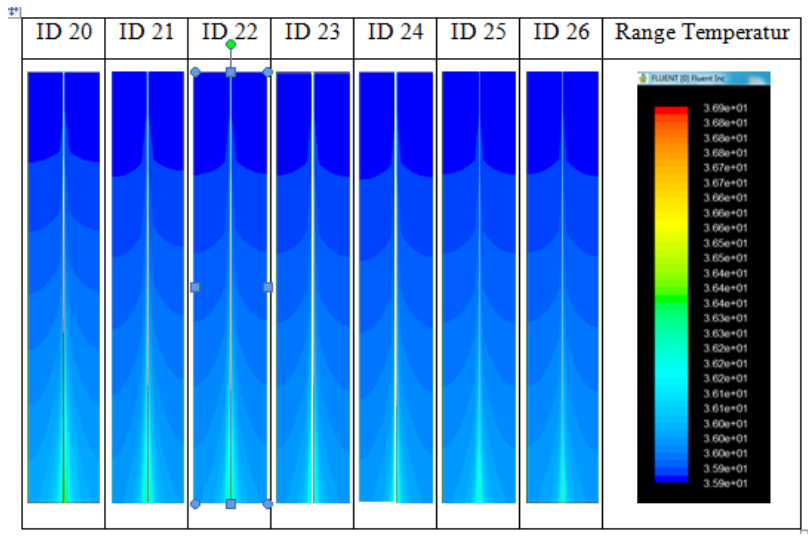

Fig. 6. Comparison of temperature distribution in the tube. 


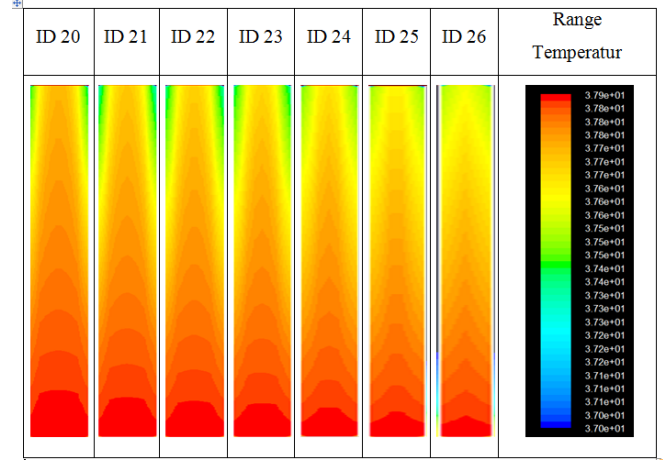

Fig. 7. Comparison of temperature distribution in the shell.

The image in the above table is the temperature distribution in the manually set shell to further clarify the increasingly fluid spreading of the natural decrease. From the comparison table above can be seen the smaller the shell area will produce the hot fluid flow section is getting smaller as well. This is due to the maximum heat transfer along with the additional tube extents. The smaller the area of the shell is due to the increase in the tube area so that it will cause a greater extent of heat fluid inside the shell. However, with the increase in diameter of the output has a similar pattern.

In addition to displaying visualization results, CFD calculations using FLUENT 6.3 can display graph plots for some of the associated magnitudes such as pressure, temperature, turbulence, etc. from one part of the model. To find the difference of heat transfer in the primary output section, the temperature value of that part will be made in the graph below.

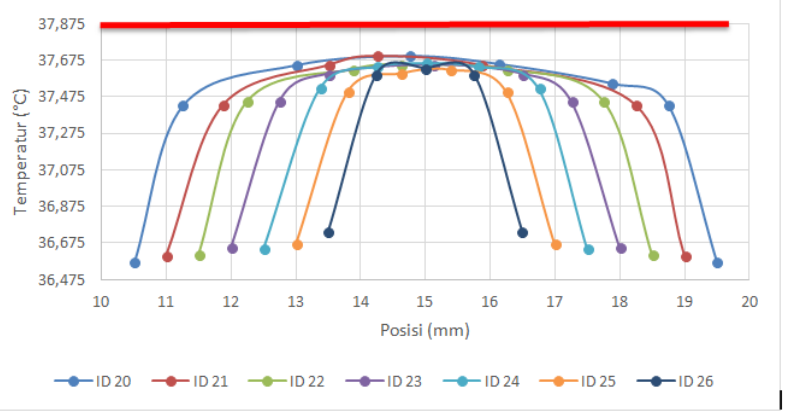

Fig. 8. Temperature Graph of Primary Output Side Model 100 $\mathrm{mm}$.

The figure above shows that the temperature distribution of different diameters has almost the same output characteristics. Thus the tube diameter variation from 20-26 mm gives the result of calculating the same output temperature. So the optimal tube diameter selection needs to be done using 3D calculations that are not done in this study, considering that in 3D model, the bigger the diameter of the pipe, the greater heat transfer surface area, so the heat that can be moved will also be greater. In this study, a 3D calculation study was also conducted to provide direction on subsequent research by selecting a diameter of $20 \mathrm{~mm}, 23 \mathrm{~mm}$ and $26 \mathrm{~mm}$.

In the picture above we can see also though the calculation technique incorporates the turbulence equation, but the flow character tends to laminar. Since the 2D model assumes that in each tube diameter variation always assume the tube media as a wall with unlimited width.

\subsection{Test the sensitivity of the model with the addition of height to $200 \mathrm{~mm}$}

To test the sensitivity of the model with a height of 100 $\mathrm{cm}$, then the addition of shell and tube length of $100 \mathrm{~mm}$. Which will then compare with the result on the $100 \mathrm{~mm}$ model for the same position.

The method performed in this CFD calculation is the same as before, the result shown is the final result until the convergent and the mesh size given is $0.8 \mathrm{~mm}$. The difference lies in the larger secondary coolant temperature input of $0.875^{\circ} \mathrm{C}$ than the previous model. As for the temperature of the primary coolant input does not change, because the extension is done to the top.

The table contains how the temperature distribution is in the tube. Can be seen that the bottom center of each image has the highest temperature. This is because the position is very close to the side of the primary coolant input. The more up, the temperature will be lower. Temperature distribution patterns, particularly on the tube portions generated on models with a height of $200 \mathrm{~mm}$ are equal to $100 \mathrm{~mm}$ models. Only its value in the same position has little difference, that is equal to $0.875^{\circ} \mathrm{C}$. This result corresponds to the difference of the primary coolant input on the $100 \mathrm{~mm}$ and $200 \mathrm{~mm}$ models.

Figure 9 below shows the comparison of temperature distributions set in the auto range. The color difference in the picture is due to the input to the secondary coolant which is calculated by involving twice the difference in input and output temperatures on a $100 \mathrm{~mm}$ high model.

If all the previous tables in the sensitivity test with model gain show the visualization of CFD calculation results without involving the calculated number, the graph below will show the temperature values on the primary output side of the primary cooler for all IDs, starting from the beginning to the end of the shell. So the results of heat transfer in primary output can be known quickly.

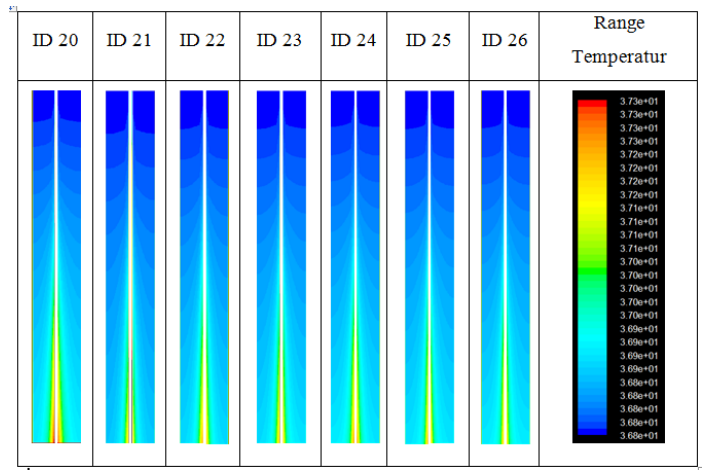

Fig. 9. Comparison of temperature distribution in the tube. 


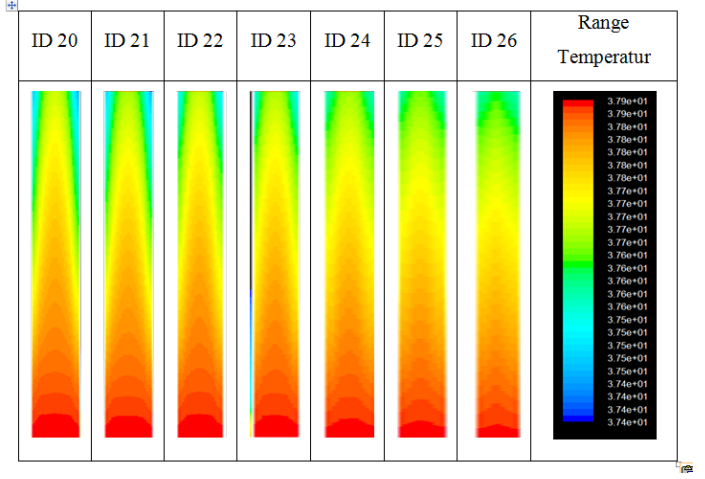

Fig. 10. Comparison of temperature distribution in the shell

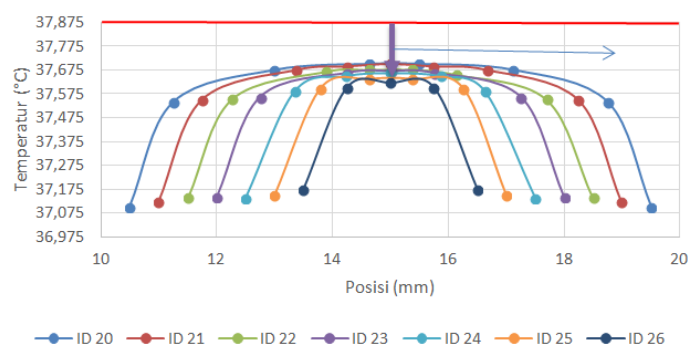

Fig. 11. Temperature Graph of Primary Output Side Model 200 $\mathrm{mm}$.

The values in the graph above can be from the plot. It aims to test the sensitivity of the $100 \mathrm{~mm}$ model. From the picture above, it can be seen that the temperature graph on the side of the primary output for the model with the height of twice the previous model is the same. The value is different. The height of $200 \mathrm{~mm}$ is the same as the extension of the $100 \mathrm{~mm}$ model or in other words two 100 $\mathrm{mm}$ models put together. The extension is performed on the tube section, so it does not affect the value of the temperature input on the primary cooler. After being compared in the same position, it is possible that the temperature in the $200 \mathrm{~mm}$ model has a higher temperature of $0.875^{\circ} \mathrm{C}$. this shows that a calculation with a length increase of $100 \mathrm{~mm}$ can support the result of the previous model $0.875^{\circ} \mathrm{C}$ this is nothing but the difference of secondary fluid input temperature at $200 \mathrm{~mm}$ by 100 $\mathrm{mm}$.

\subsection{D modeling with ID that have optimal temperature transfer}

In accordance with the analysis on the $2 \mathrm{D}$ model, that in this $3 \mathrm{D}$ case, the ID to be counted is ID 20, 23 and $26 \mathrm{~mm}$. The steps taken to simulate the $3 \mathrm{D}$ model is the same as the 2D model. Discussion and analysis are done after the convergence is achieved for each model. To achieve the convergence of 3D models takes a much longer time compared to the 2D model. This is due to the large number of mesh. To see the number of iterations until the convergence is achieved can be seen in Table 3. To see the temperature distributions in the shell and tube are shown in Table 8.
Table 3.Convergence table for ID $20 \mathrm{~mm}, 23 \mathrm{~mm}$, and $26 \mathrm{~mm}$.

\begin{tabular}{|c|c|}
\hline ID & Number of Iterations \\
\hline 20 & 480 \\
\hline 23 & 565 \\
\hline 26 & 742 \\
\hline
\end{tabular}

From table 3, it can be seen that the more up, the fluid in the tube increases the temperature seen also the fluid that flows on the side of the wall has the highest temperature. This is due to the direct contact with the wall between the fluid on the primary and secondary coolers.

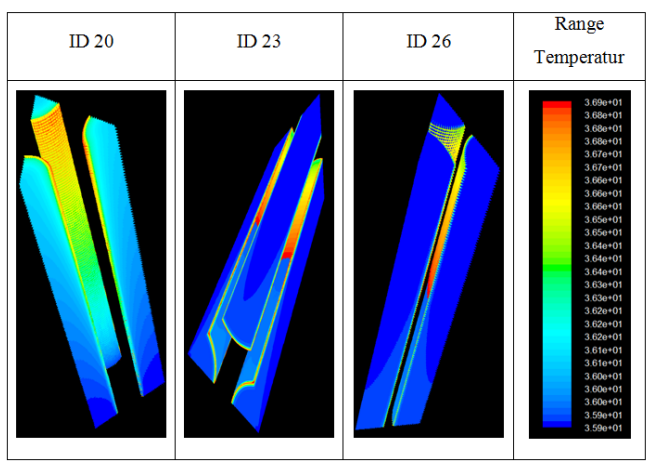

Fig. 12. Comparison of temperature distribution in tubes.

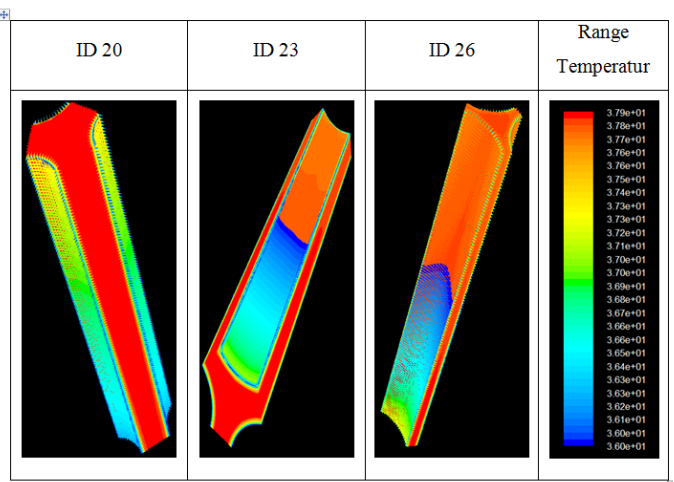

Fig. 13. Comparison of temperature distribution in shell.

Grafik Penurunan Tekanan dalam Arah Sumbu-Z

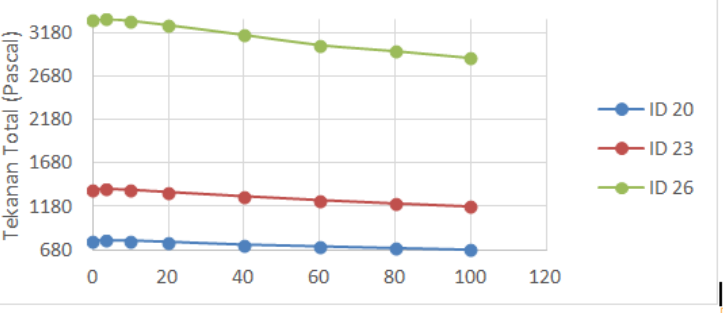

Fig. 14. Pressure drop graph for ID $20 \mathrm{~mm}, 23 \mathrm{~mm}$, and $26 \mathrm{~mm}$.

For further discussion, the analysis of the resulting data will be fed from the pressure drop that occurs in the primary coolant. From the picture above can be seen that the increase in pressure drop is proportional to the 
increment ID. The largest pressure drop is generated by a model with a $26 \mathrm{~mm}$ ID of $450 \mathrm{~Pa}$ with a maximum pressure value of $3333 \mathrm{~Pa}$ and a minimum of $2883 \mathrm{~Pa}$. For ID $23 \mathrm{~mm}$, the maximum pressure value is $1374 \mathrm{~Pa}$ and the minimum is $1175 \mathrm{~Pa}$, resulting in a pressure drop value of $199 \mathrm{~Pa}$. From the simulation results for ID $20 \mathrm{~mm}$ pressure drop that occurred at $108 \mathrm{~Pa}$ with the maximum and minimum value respectively $788 \mathrm{~Pa}$ and $680 \mathrm{~Pa}$. In this experiment the fluids in both primary and secondary coolers use the same fluid. In addition, the above graph is generated from a line plot in the center of the shell so that the results of the calculations also use the same flow rate. In this case pressure drop is caused by the friction factor. The increasing value of friction factor is caused by the increase of ID.

Table 4. Minimum Temperature in Primary Output.

\begin{tabular}{|l|l|l|}
\hline $\mathrm{ID}(\mathrm{mm})$ & Minimum $(\mathrm{K})$ & $\Delta \mathrm{T}\left({ }^{\circ} \mathrm{C}\right)$ \\
\hline 20 & 310,93814 & 0,08686 \\
\hline 23 & 310,93826 & 0,08674 \\
\hline 26 & 310,92831 & 0,09669 \\
\hline
\end{tabular}

By using FLUENT 6.3 software we can know the value of a physical quantity such as temperature at a certain point. The trick is to make a line if the simulated model is classified as $2 \mathrm{D}$ or by creating an area for the $3 \mathrm{D}$ model. For comparison materials, the following table presents the area inside the primary output side that has a minimum temperature. From Table 4.10, it can be seen that the $26 \mathrm{~mm}$ ID has the lowest exit temperature compared to the other ID. This is due to the large transfer area resulting in the most optimal heat transfer.

\section{Conclusion}

Simply put, the Heat Exchanger is a set of tools used to transfer some of the heat from the hot fluid to the coolertempered fluid. In this case Heat Exchangers are used with Shell and Tube types so that heat transfer occurs from the shell through which the hot fluid flows to the tube through which the cold fluid passes.

The heat fluid that enters the shell comes from the RSG-GAS research reactor which will then be converted to the primary refrigerant preference through the Heat Exchanger so that the fluid experiences a decrease in temperature.

In the 2D model, the flow that occurs tends to laminar flow because in this model the boundary wall between tube and shell is considered infinite. Because it also causes to get the optimal ID required 3D calculations.

The most optimal heat transfer is generated by ID 26 $\mathrm{mm}$. The heat absorbed by the primary coolant is about $0.09669{ }^{\circ} \mathrm{C}$. Due to the influence of friction factor, there is pressure drop in each model. The highest pressure drop value is generated by ID 26 which is $450 \mathrm{~Pa}$.

We say many thanks to Research and Publication Center of UIN Sunan Gunung Djati Bandung Indonesia for supporting publication of our research.

\section{References}

1. P. M. Laksono, A. . Mundayat, Y. T. Subagya, and Y. W. Nuraini, Rencana pembangunan PLTN di Indonesia. Yogyakarta: Gajah Mada University Press, 1993.

2. Purwadi and M. Dhandhang., "Pendekatan untuk manajemen penuaan RSG-GAS," in Prosiding seminar hasil penelitian P2TRR, 2003.

3. M. Subekti and M. D. Purwadi, Apakah PLTN itu. Serpong: PTRKN BATAN.

4. F. H. Napitupulu, "Kajian Eksperim ental Efektivitas Alat penukar Kalor Shell and tube sebagai Pemanas Air dengan memanfaatkan energi termal gas buang motor diesel," J. Ilm. Saintek, vol. 22, no. 2, 2005.

5. A. Alimoradi, "Optimal and critical values of geometrical parameters of shell and helically coiled tube heat exchangers," Case Stud. Therm. Eng., 2017.

6. P. K. Swamee, N. Aggarwal, and V. Aggarwal, "Optimum design of double pipe heat exchanger," Int. J. Heat Mass Transf., vol. 51, pp. 2260-2266, 2008.

7. C. Pan, T. Zhang, J. Wang, and Y. Zhou, "International Journal of Thermal Sciences CFD study of heat transfer and pressure drop for oscillating fl ow in helical rectangular channel heat exchanger," Int. J. Therm. Sci., vol. 129, pp. 106$114,2018$.

8. K. Somasekhar, K. N. D. M. Rao, V. Sankararao, R. Mohammed, M. Veerendra, and T. Venkateswararao, "A CFD Investigation of Heat Transfer Enhancement of Shell and Tube Heat Exchanger Using Al2o3 -Water Nanofluid," Mater. Today Proc., vol. 5, pp. 1057-1062, 2018.

9. V. Dvořák and T. Vít, "CAE methods for plate heat exchanger design," Energy Procedia, vol. 134, pp. 234-243, 2017.

10. I. Saputra, "Optimasi Desain Alat Penukar Kalor ( Shell and Tube ) Jenis Cangkang dan Pipa untuk Pendinginan," J. Ilm. Teknobiz, vol. 5, no. 1, pp. 15, 2015.

11. M. Mirzaei, H. Hajabdollahi, and H. Fadakar, "Multi-objective optimization of shell-and-tube heat exchanger by constructal theory," Appl. Therm. Eng., pp. 1-38, 2017.

12. X. Zhang, P. Tseng, M. Saeed, and J. Yu, "Annals of Nuclear Energy A CFD-based simulation of fluid flow and heat transfer in the Intermediate Heat Exchanger of sodium-cooled fast reactor," Ann. Nucl. Energy, vol. 109, pp. 529-537, 2017.

13. Z. Cheng, Z. Tao, J. Zhu, and H. Wu, "Diameter effect on the heat transfer of supercritical hydrocarbon fuel in horizontal tubes under turbulent conditions," Appl. Therm. Eng., vol. 134, pp. 39-53, 2018. 